
Technologies

\title{
Development of Practical HPLC Methods for the Separation and Determination of Eggplant Steroidal Glycoalkaloids and their Aglycones
}

\section{Ritchie C. Eanes, Neslihan Tek, Oykum Kirsoy , Anne Frary , Sami Doganlar} \& Adelia E. Almeida

To cite this article: Ritchie C. Eanes, Neslihan Tek, Oykum Kirsoy , Anne Frary , Sami Doganlar \& Adelia E. Almeida (2008) Development of Practical HPLC Methods for the Separation and Determination of Eggplant Steroidal Glycoalkaloids and their Aglycones, Journal of Liquid Chromatography \& Related Technologies, 31:7, 984-1000, DOI: $10.1080 / 10826070801924741$

To link to this article: http://dx.doi.org/10.1080/10826070801924741

\section{Published online: 31 Mar 2008}

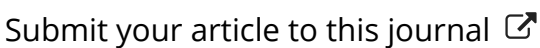

Џ Article views: 156

Q View related articles ¿

Citing articles: 8 View citing articles 주 


\title{
Development of Practical HPLC Methods for the Separation and Determination of Eggplant Steroidal Glycoalkaloids and their Aglycones
}

\author{
Ritchie C. Eanes, ${ }^{1}$ Neslihan Tek, ${ }^{1}$ Oykum Kirsoy, ${ }^{2}$ \\ Anne Frary, ${ }^{2}$ Sami Doganlar, ${ }^{2}$ and Adelia E. Almeida ${ }^{3}$ \\ ${ }^{1}$ Izmir Institute of Technology, Chemistry Department, Urla, Izmir, \\ Turkey \\ ${ }^{2}$ Izmir Institute of Technology, Biology Department, Urla, Izmir, Turkey \\ ${ }^{3}$ Faculty of Pharmaceutical Sciences, Sao Paulo State University, \\ Sao Paulo, Brazil
}

\begin{abstract}
A practical set of HPLC methods was developed for the separation and determination of the eggplant steroidal glycoalkaloids, solanine, chaconine, solasonine, solamargine, and their aglycones, solasodine and solanidine. A gradient method was initially developed, but proved to be neither robust nor practical. Three separate isocratic methods using acetonitrile and ammonium dihydrogen phosphate were developed and shown to be more repeatable, less subject to fluctuations in mobile phase composition, and less time consuming. The effect of adjusting buffer $\mathrm{pH}$, column temperature, and buffer type (triethylammonium phosphate vs. ammonium dihydrogen phosphate) were evaluated. It was also discovered that, by addition of $10 \%$ methanol to the acetonitrile portion of the mobile phase, more control over the separations was possible. The use of methanol as a mobile phase entrainer greatly improved separations in some cases and its effectiveness was also dependent upon column temperature. Assessments of the method recovery, limit of detection, and limit of quantitation were made using extracts from S. melongena and S. linnaeanum.
\end{abstract}

Keywords: HPLC, Eggplant, Solanine, Chaconine, Solamargine, Solasonine, Solanidine, Solasodine, Steroidal glycoalkaloids

Correspondence: Ritchie C. Eanes, Izmir Institute of Technology, Chemistry Department, Urla, Izmir, Turkey 35430. E-mail: ritchieeanes@iyte.edu.tr 


\section{INTRODUCTION}

Especially in the areas in, or related to, food science, toxicology, and pharmacology, steroidal glycoalkaloids (SGAs) and their aglycones (SGAAs) have received attention. ${ }^{[1-5]}$ Found particularly in wild-type members of the genus Solanum, such as varieties of tomato, potato, and eggplant,${ }^{[2]}$ these compounds are regarded as toxic. ${ }^{[6-8]}$ However, researchers have also reported and referenced the use of certain glycoalkaloids for use in anti-cancer medications, ${ }^{[9-14]}$ for their medicinal or bioactive properties, ${ }^{[15,16]}$ for their utility as precursors to the synthesis of useful pharmaceuticals, ${ }^{[5]}$ and for their anti-fungal properties. ${ }^{[17]}$ The interest in extracting these compounds and using them for medicinal purposes is shown, as well, in the form of several patents or patent applications. ${ }^{[18-26]}$

Descriptions of the chemical structures for these similar compounds are found in the literature. ${ }^{[3-5]}$ Due to the difficulty in the practical separation of all these compounds for rapid analysis, ${ }^{[27]}$ sometimes researchers in this field base their determinations solely on the hydrolysis products and not the actual glycoalkaloids (SGAs); moreover, the aglycones can further hydrolyze, making such determinations of aglycone "equivalents" inaccurate. ${ }^{[28]}$ Methods for the analysis of glycoalkaloids have primarily focused on the potato. ${ }^{[29-41]}$ Exceptions to this are seen, for example, in the works of Aubert et al. who used HPLC for the the analysis of glycoalkaloids present in the eggplant variety Solanum melongena ${ }^{[42,43]}$ and Fukuhara et al. who used countercurrent chromatography for the separation of glycoalkaloids in Solanum incanum. ${ }^{[4]}$ Several authors have explored novel methods for the determination of glycoalkaloids in recent years. Among these are the use of enzyme-linked immunosorbent assay (ELISA), which is useful only for the aglycone forms, ${ }^{[45]}$ "fluorescence polarization immunoassay,"[46] "solution phase immunoassay with capillary electrophoresis, ${ }^{[47]}$ gas chromatography mass spectrometry as applied to the aglycone forms, ${ }^{[48]}$ liquid chromatography mass spectrometry, ${ }^{[38,49]}$ matrix-assisted laser-desorption/ ionization time-of-flight mass spectrometry (MALDI-TOF/MS), ${ }^{[50]}$ "nonaqueous capillary electrophoresis with ultra violet (UV) detection (NACEUV)" for the analysis of solasodine and solanidine aglycones, ${ }^{[51,52]} \mathrm{NACE}$ combined with ion-trap mass spectrometry, ${ }^{[52,53]}$ and, lastly, derivatization of the glycoalkaloids followed by HPLC separation and chemiluminescence detection. ${ }^{[54]}$ Each of these methods has its own particular merits; however, although glycoalkaloids show limited absorption of ultraviolet (UV) light, HPLC separation followed by UV detection can still be considered a viable method, due to the relative widespread availability of this instrumentation and the potential to detect not some, but all the glycoalkaloids of interest without a lengthy derivatization step. Investigating improvements to existing HPLC methods for the separation and analysis of the steroidal glycoalkaloids (SGAs) solanine, chaconine, solasonine, solamargine, and their aglycones (SGAAs) solanidine and solasodine was the primary focus of the 
work presented here, which will be useful for future collaborative studies in this lab. A serendipitous outcome of the present work was the discovery of the benefits related to using methanol as a mobile phase modifier for the improved control of the HPLC separation of these compounds.

\section{EXPERIMENTAL}

\section{Chemicals, Materials}

All standards were obtained commercially, except for solamargine, which was provided by Prof. Dr. Adelia Emila de Almeida (Faculdade de Ciencias Farmaceuticas-UNESP, Brazil). Alpha-solanine, $\alpha$-chaconine, and progesterone were obtained from Sigma Aldrich (Germany). Solasodine and solanidine were obtained from both MP Biochemicals (OH, USA) and Research Plus (NJ, USA). Solasonine was obtained from Research Plus (NJ, USA). HPLC-grade acetonitrile (Sigma Aldrich, Germany) and methanol (Riedel-de Haen) were used for HPLC analysis. Ammonium dihydrogen phosphate (>99\%) was purchased from Merck (Germany); $1.0 \mathrm{mM}$ triethylammonium phosphate (TEAP) and $1.0 \mathrm{mM}$ tris(hydroxymethyl)-aminomethane hydrochloride (Tris- $\mathrm{HCl}$ ) were purchased from Fluka (Switzerland). All buffer solutions were filtered through $0.45-\mu \mathrm{m}$ pore-size polyamide filters (Sartorius, Germany) and sonicated. Standards were prepared in acetonitrile-water $(1 / 1$ $\mathrm{v} / \mathrm{v}$ ) acidified with orthophosphoric acid and stored at $4{ }^{\circ} \mathrm{C}$. Both $\mathrm{NH}_{2}$ Nucleosil and $\mathrm{C}_{18}$ Nucleosil columns were purchased from HiChrom (USA). Initial work with the $\mathrm{NH}_{2}$ column showed little success; therefore, only the $\mathrm{C}_{18}$ column was used for these studies.

\section{Extraction}

The final method developed for extraction of glycoalkaloids from eggplant material was based on modification and consideration of the varied procedures as applied to the potato by Kuronen et al. ${ }^{[27]}$ Saito, ${ }^{[29]}$ Friedman and Levin, ${ }^{[30]}$ Dao and Friedman, ${ }^{[33]}$ Sotelo and Serrano, ${ }^{[36]}$ Friedman et al., ${ }^{[39]}$ and as applied to Solanum sycophanta by Usubillaga et al. ${ }^{[55]}$ Analogous to classical precipitation/crystallization procedures for the extraction of solanine from potato, ${ }^{[56]}$ initial attempts were made to extract the glycoalkaloids from eggplant by prescribed methods that involved collection of either a residue ${ }^{[36]}$ or a precipitate. ${ }^{[39]}$ However, such routes were abandoned because acceptable collection of a precipitate/residue of suitable purity and accurately measured mass was either not possible or not feasible, especially when considering that the final method would eventually be applied to a large set of samples. Instead, it was deemed preferable to keep the extracts in solution throughout the entire analysis. 
Samples of commercial eggplant (Solanum melongena), commercial eggplant spiked with known amounts of glycoalkaloid standard, and wild eggplant (Solanum linnaeanum) were used for these experiments. Specifically, the wild type eggplant fruits used for this work had been freeze-dried, vacuum-packed, and received from Dr. Marie-Christine Daunay of INRA Unite de Genetique \& Amelioration des Fruits et Legumes (Montfavet cedex, France). All samples were stored at $-80^{\circ} \mathrm{C}$ until use. Samples were ground to a fine powder under high purity nitrogen in a specially designed Glove-Bag ${ }^{\mathrm{TM}}$ ( ${ }^{2} \mathrm{R}$ Glas-Col, Terre Haute, IN) environment to minimize exposure to humidity, and was then immediately placed in a dessicator. Depending upon the expected glycoalkaloid content of the eggplant, varying amounts of ground material were used, ranging from $0.25 \mathrm{~g}$ to several grams. In general, $1.0 \mathrm{~g}$ of ground powder was used for extraction. Duplicate $1.0 \mathrm{~g}$ samples of this powder were then separately added to extraction mixtures of $40 \mathrm{~mL}$ methanol-5\% acetic acid solution in $50 \mathrm{~mL}$ conical tubes. The tubes were mechanically shaken overnight to ensure good mixing, but with care to prevent possible emulsion formation. Each extract was filtered through a type 1575 (90 mm diameter) filter paper (Schleicher \& Schuell Microscience, Germany) using a Buchner funnel and vacuum pump. Then, each sample was filtered again through a $0.45-\mu \mathrm{m}$ pore-size polyamide filter via vacuum filtration to remove any remaining debris. The extraction solution was then evaporated to a volume of $8-9 \mathrm{~mL}$, filtered through a 0.2 micrometer syringe filter into a $10-\mathrm{mL}$ volumetric flask, and diluted to analytical volume with the same methanol-5\% acetic acid solution. The extract was then kept at $4^{\circ} \mathrm{C}$ until measurement by HPLC.

\section{High Performance Liquid Chromatographic Separation}

A Shimadzu Class-VP (Kyoto, Japan) single piston high-pressure liquid chromatograph with photodiode array detection was used. UV detection at 205 and $208 \mathrm{~nm}$ was chosen. Both isocratic and gradient elution methods were employed. For all work, a binary mobile phase system was set up where one delivery bottle contained the organic solvent (ACN for all work) and was designated "B". The second delivery bottle contained the buffer (Tris-HCl, TEAP, or ammonium dihydrogen phosphate).

To improve precision in both measurement of retention times and signal intensities, progesterone was used as an internal standard for the determination of the SGAAs. Progesterone has structural similarities to the aglycones and is economical to obtain. Also, for each prepared extraction solution, at least two separate HPLC injections were performed to ensure instrumental reproducibility. 


\section{RESULTS AND DISCUSSION}

\section{Problems with Gradient Elution}

In contrast to the work of Vaananen et al., ${ }^{[37]}$ the required gradient method for this work was quite complex and did not provide robust and acceptable separation of the eggplant SGAs of interest over the course of several months. Also, it proved to be impractically slow, since the start of each injection required that the column be re-equilibrated to the starting concentration of the gradient. This problem was exacerbated by the need to run the gradient several times, both with and without injection of sample, to ensure both stability and reproducibility of the HPLC gradient system while, at the same time reducing the chance of possible memory effects from injection to injection. Furthermore, due to the dramatic change in column pressure during the course of the gradient method, an expected drastic shift in the chromatographic baseline always occurred approximately 15 minutes after injection. Since one gradient run consumed nearly an hour from injection to injection, it was decided that two or three separate isocratic methods would consume less time and mobile phase. Therefore, further attempts to improve or use a gradient method were abandoned. Unless otherwise noted, all subsequent work described hereafter was performed using isocratic HPLC.

\section{Effect of Buffer Type}

Two different buffers, ammonium dihydrogen phosphate (denoted here as $\left.\mathrm{AH}_{2} \mathrm{P}\right)(100 \mathrm{mM})$ and TEAP $(25 \mathrm{mM})$, acidified to $\mathrm{pH} 2.5$ with $85 \%$ orthophosphoric acid, were evaluated at $26^{\circ} \mathrm{C}$ and $50^{\circ} \mathrm{C}$. The optimal isocratic solvent conditions were $30 \% \mathrm{ACN}$ and $70 \%$ buffer (either TEAP or $\mathrm{AH}_{2} \mathrm{P}$ ) for the separation of the SGAs, but $60 \% \mathrm{ACN}$ and $40 \%$ buffer was necessary for the elution of the SGAAs. Further increases in percent ACN (e.g., to 75\%) caused precipitation of ammonium dihydrogen phosphate $(100 \mathrm{mM})$ in the HPLC plumbing, as should be expected. ${ }^{[57]}$ Ammonium dihydrogen phosphate buffer, in general, produced better separations of the SGAs that could also be tailored between $26^{\circ} \mathrm{C}$ (Fig. 1) and $50^{\circ} \mathrm{C}$ (Fig. 2). The SGAAs (solanidine and solasodine) were separated adequately when using either the TEAP or ammonium dihydrogen phosphate $\left(\mathrm{AH}_{2} \mathrm{P}\right)$ buffers, but the peaks were narrower when ACN/ammonium dihydrogen phosphate buffer was used. Moreover, when using the TEAP buffer, there was an apparent interference to the internal standard (Fig. 3). Therefore, ammonium dihydrogen phosphate $(100 \mathrm{mM})$ was ultimately selected as the more useful buffer, since it produced better separations of the SGAs under isocratic conditions and was more economical to obtain than TEAP. This was also expected from a colleague's suggestion from 

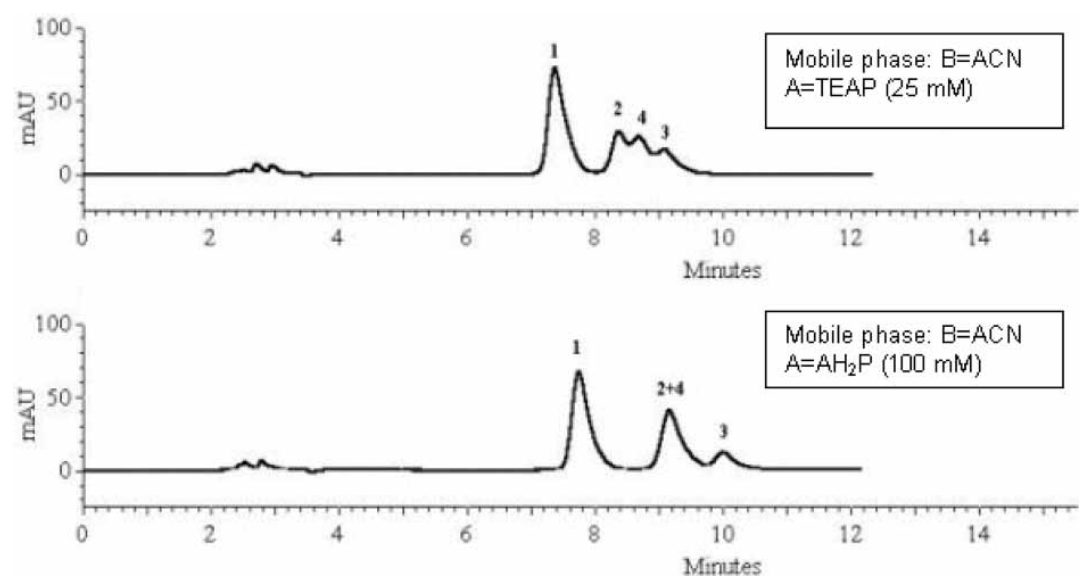

Figure 1. Effect of buffer type on separation of SGAs. Temperature: $26^{\circ} \mathrm{C}$, Flow rate: $1.0 \mathrm{~mL} / \mathrm{min} \mathrm{pH:} 2.5$ 1: solasonine 2: $\alpha$-solanine 3: $\alpha$-chaconine 4: solamargine.

his work with glycoalkaloids in eggplant, ${ }^{[58]}$ and gives support to the use of ammonium dihydrogen phosphate as a buffer of choice for the HPLC separation of eggplant glycoalkaloids when using a $\mathrm{C}_{18}$ column. Furthermore, compared to ammonium dihydrogen phosphate, TEAP has a limited shelf life, as noted by the chemical producers, ${ }^{[59]}$ which may partially explain the interferences seen near the retention time of the progesterone internal standard when using this buffer.
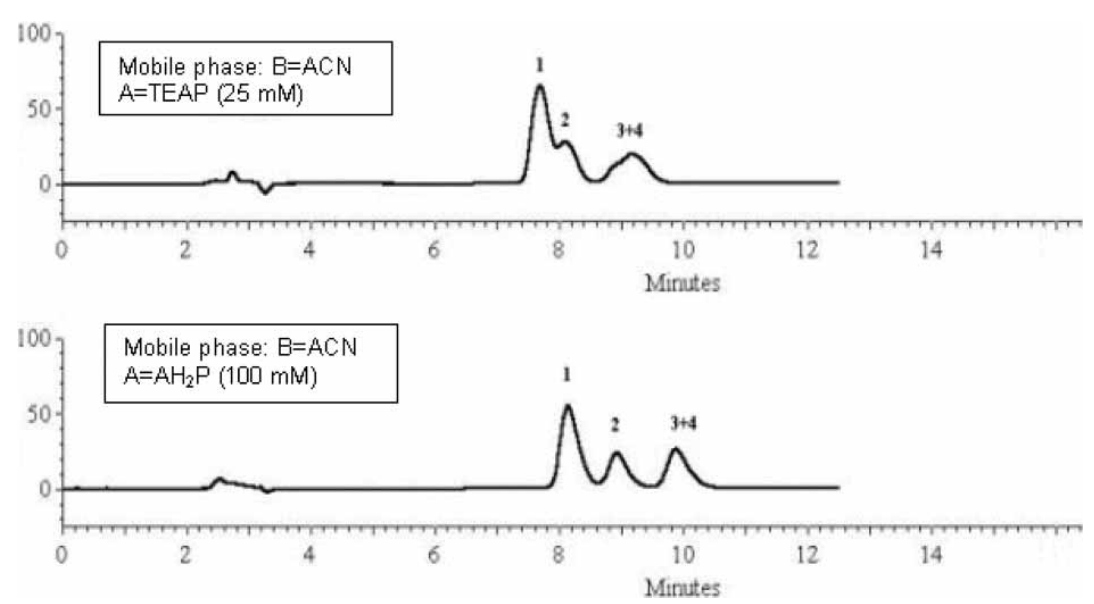

Figure 2. Effect of buffer type on separation of SGAs. Temperature: $50^{\circ} \mathrm{C}, \mathrm{pH}: 2.5$ Flow rate: $1.0 \mathrm{~mL} \mathrm{1:} \mathrm{solasonine} \mathrm{2:} \alpha$-solanine 3: $\alpha$-chaconine 4: solamargine. 

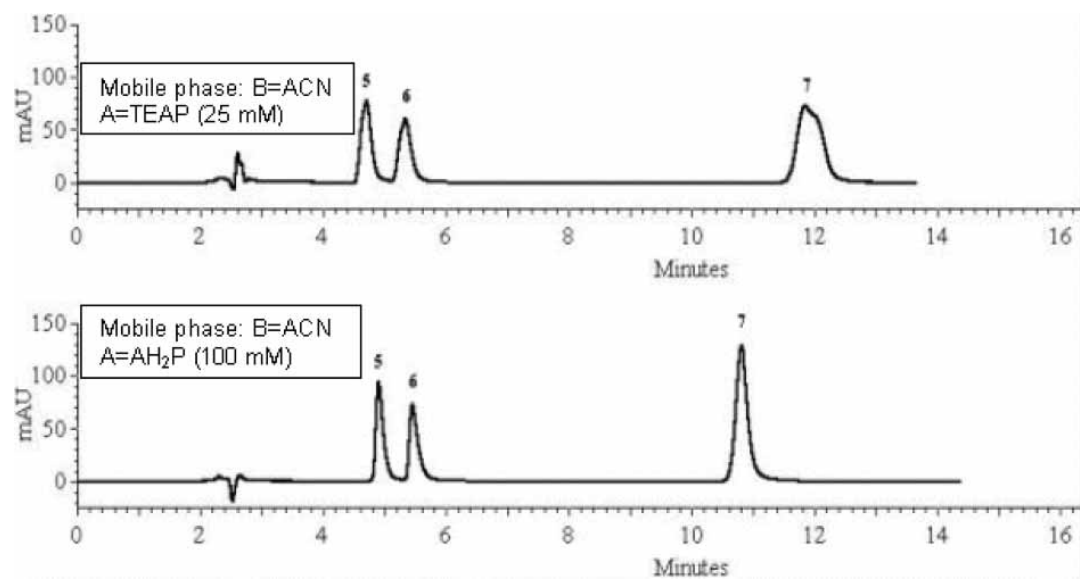

Figure 3. Effect of buffer type on the separation of SGAAs. Temperature: $50^{\circ} \mathrm{C}, \mathrm{pH}$ : 2.5 F: $1.0 \mathrm{~mL} / \mathrm{min}$ 5: solanidine 6: solasodine 7: progesterone (internal standard).

\section{Effect of Temperature}

Figure 4 shows the chromatograms obtained when using the ACN/ammonium dihydrogen phosphate buffer $(100 \mathrm{mM})(30 / 70)$ mobile phase system at two different temperatures. It can be seen that the peaks for solanine and chaconine were not separated acceptably at $26^{\circ} \mathrm{C}$. At a higher temperature, the SGAAs eluted earlier and the peaks were sharper, as compared with those at lower temperature (Fig. 5). Although the use of TEAP was abandoned, it is
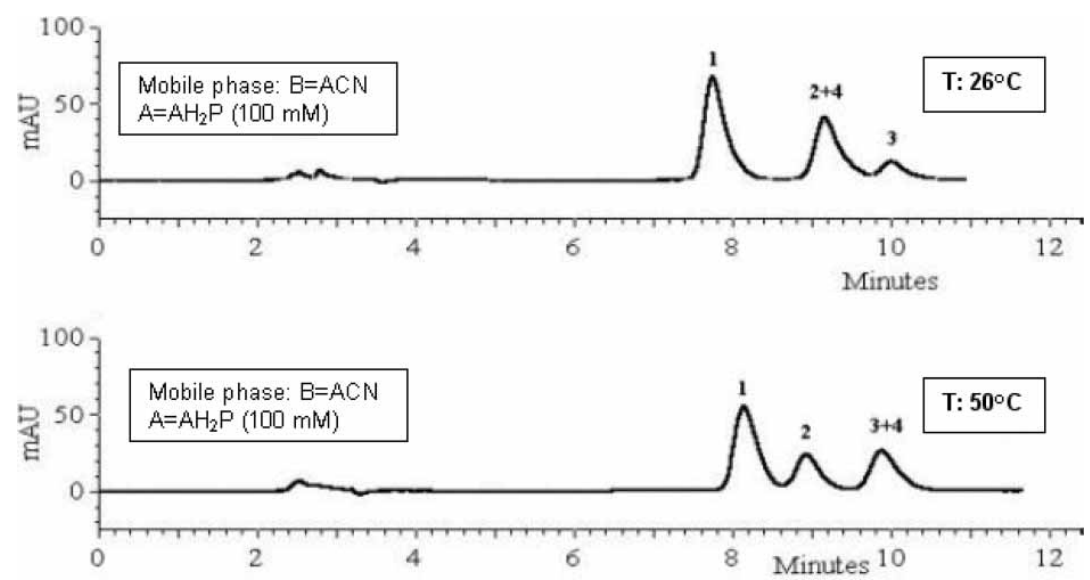

Figure 4. Effect of temperature $(\mathrm{T})$ on the separation of SGAs. pH: 2.5, Flow rate: $1.0 \mathrm{~mL} / \mathrm{min}$ 1: solasonine 2: $\alpha$-solanine 3: $\alpha$-chaconine 4: solamargine. 


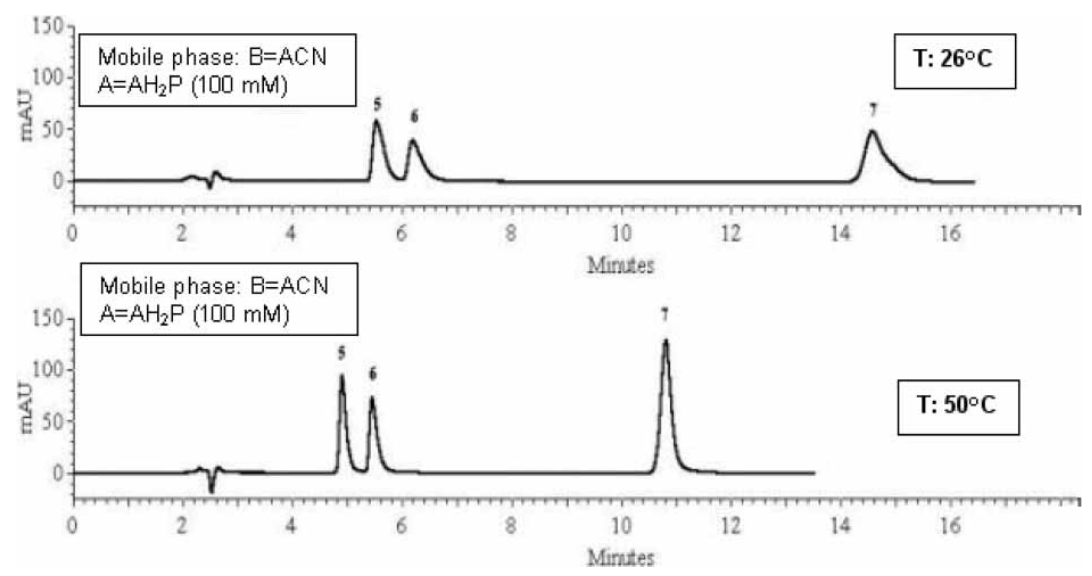

Figure 5. Effect of temperature (T) on the separation of SGAAs. pH: 2.5 Flow rate: $1.0 \mathrm{~mL} / \mathrm{min}$ 5: solanidine 6: solasonine 7: progesterone (internal standard).

worth noting that when TEAP buffer was used, temperature also influenced the separations in a similar manner.

\section{Using Methanol as a Mobile Phase Modifier}

A unique aspect of this work was the investigation of methanol $(\mathrm{MeOH})$ as an entrainer (modifier). At $26^{\circ} \mathrm{C}$, and with the addition of $\mathrm{MeOH}(10 \%)$ to the ACN portion of the isocratic mobile phase (mobile phase solvent B), solanine could be separated from the overlapping chaconine and solamargine (Fig. 6). At $50^{\circ} \mathrm{C}$, addition of $10 \% \mathrm{MeOH}$ to $\mathrm{ACN}$ allowed the baseline separation of chaconine from solamargine (Fig. 7). At both temperatures, not only did the separation of solanidine and solasodine (SGAAs) improve, but also the overall retention times of both of these analytes were extended by manipulating the amount of methanol in ACN, as shown in Fig. 8. To the best of our knowledge, this is the first time that the use of methanol in this manner has been shown to improve the separation of solamargine and chaconine. These results clearly show the importance of considering both column temperature and the use of a mobile phase modifier for the separation of these types of compounds.

\section{Effect of pH}

Figure 9 illustrates separations at different $\mathrm{pH}$ values when using ammonium dihydrogen phosphate as buffer. There was no significant effect in the separation of the glycoalkaloids upon increasing the $\mathrm{pH}$ of the buffer of the mobile 

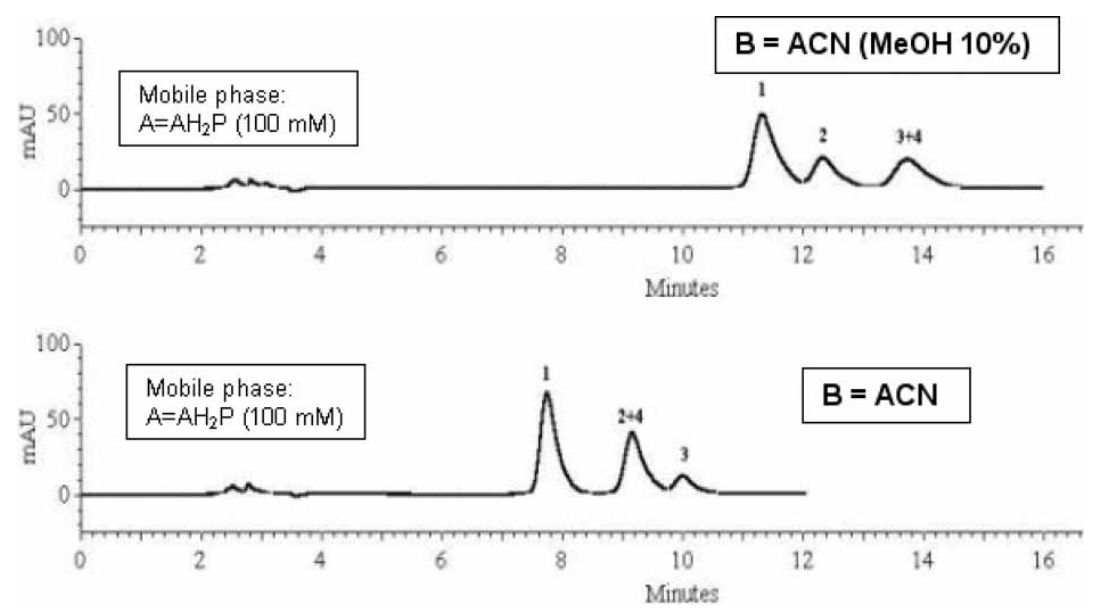

Figure 6. Methanol entrainer and separation of SGAs. Temperature $26^{\circ} \mathrm{C}, \mathrm{pH}: 2.5$ Flow rate: $1.0 \mathrm{~mL} / \min 1$ : solasonine 2: $\alpha$-solanine 3: $\alpha$-chaconine 4: solamargine.

phase from 2.5 to 4.5 , except for an overall increase in retention times for all SGAs and SGAAs.

\section{Practical HPLC Conditions}

According to their potential to overlap, three isocratic methods were developed for each of the following three compound group pairs: solamargine
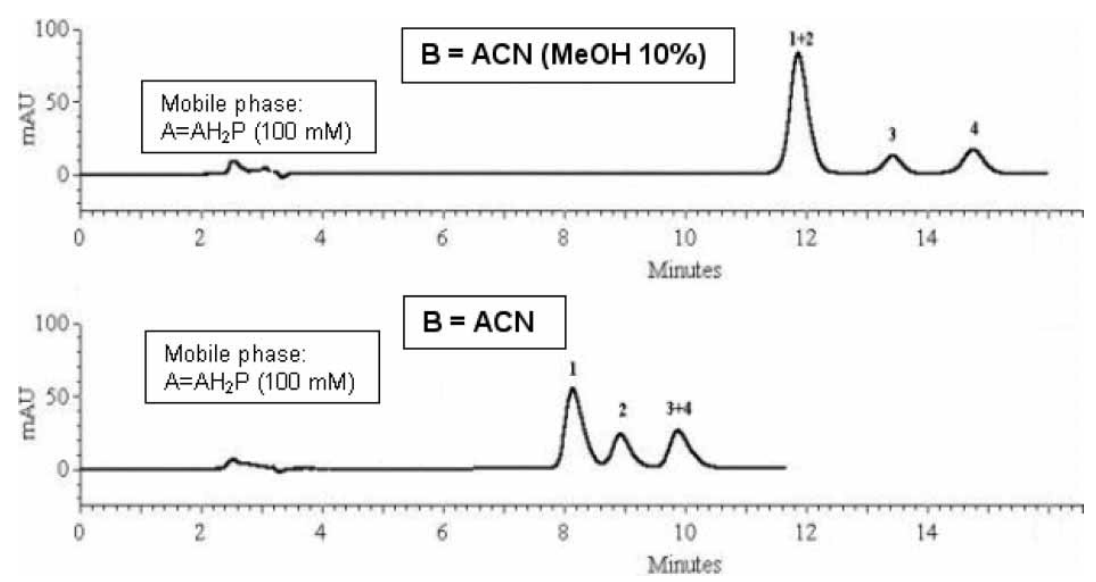

Figure 7. Methanol entrainer and separation of SGAs. Temperature $50^{\circ} \mathrm{C}, \mathrm{pH}: 2.5$ Flow rate: $1.0 \mathrm{~mL} / \mathrm{min} 1$ : solasonine 2: $\alpha$-solanine 3: $\alpha$-chaconine 4: solamargine. 

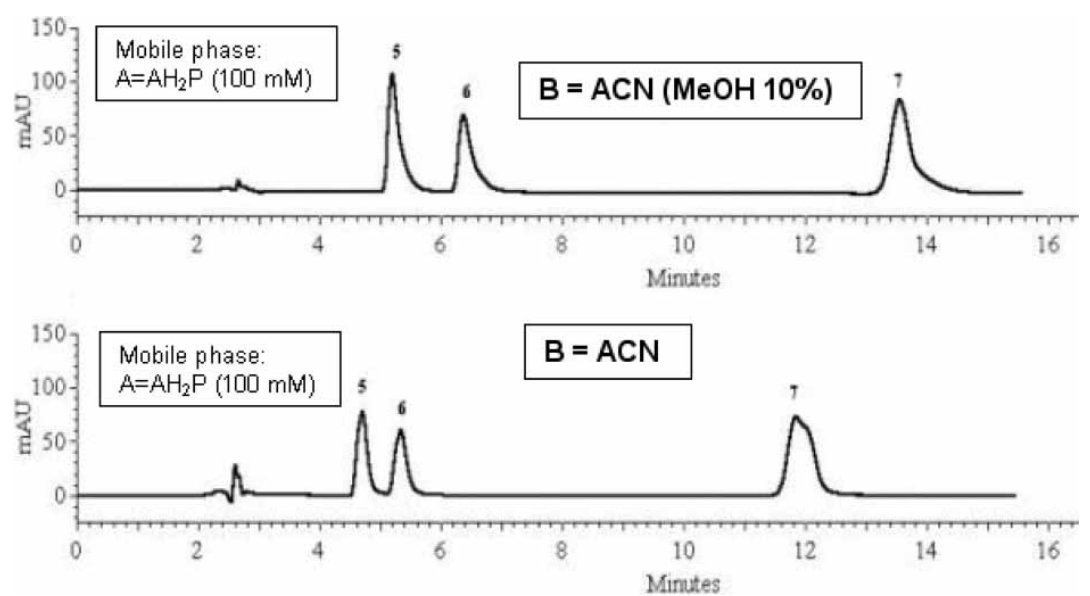

Figure 8. Methanol entrainer and separation of SGAAs. Temperature: $50^{\circ} \mathrm{C} \mathrm{pH:} 2.5$ Flow rate: $1.0 \mathrm{~mL} / \mathrm{min}$ 5: solanidine 6: solasodine 7: progesterone as internal standard.

and chaconine, solanine and solasodine, and the aglycones solasodine and solanidine. The best set of conditions found for the separation of solamargine and chaconine were found to be as follows: $\mathrm{ACN}(10 \% \mathrm{MeOH}) /$ ammonium dihydrogen phosphate buffer $(30 / 70), \mathrm{pH}: 2.5$, column temperature $50^{\circ} \mathrm{C}$
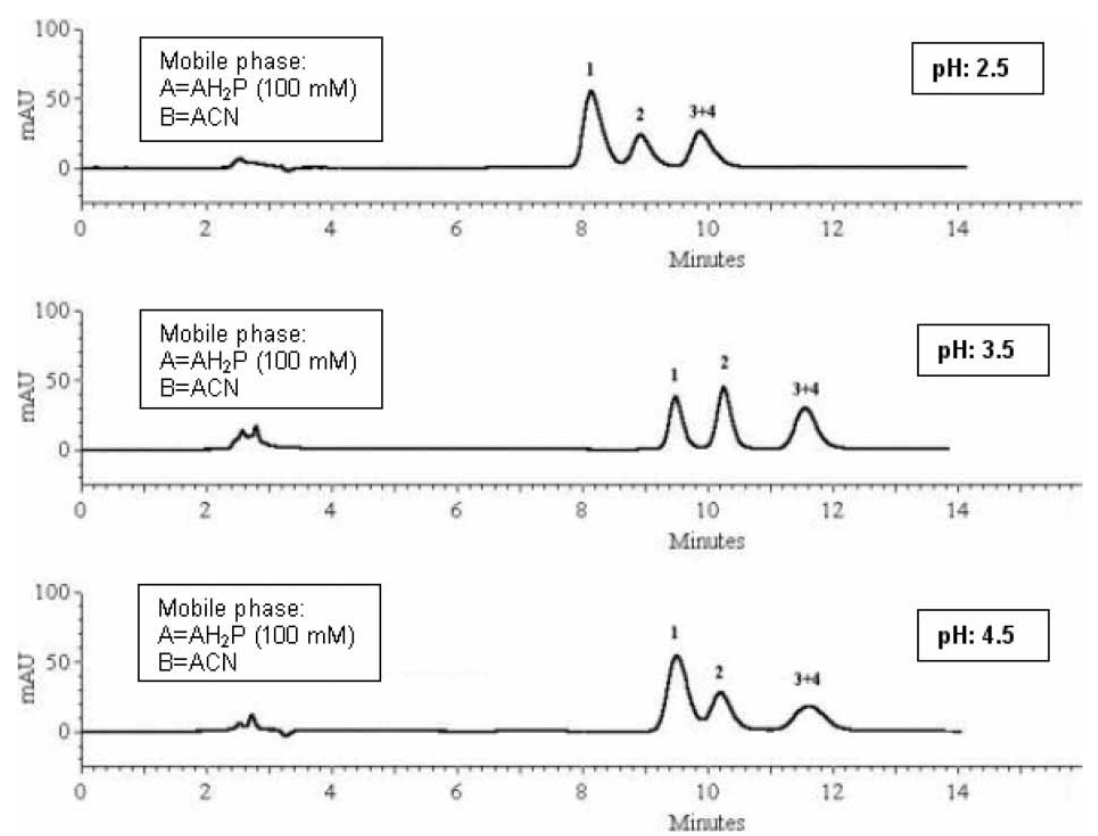

Figure 9. Effect of $\mathrm{pH}$ on the separation of SGAs. Temperature: $50^{\circ} \mathrm{C}$ Flow rate: $1.0 \mathrm{~mL} / \min 1$ : solasonine 2: $\alpha$-solanine 3: $\alpha$-chaconine 4: solamargine. 
(Method 1). Solanine and solasonine could be well separated under the same conditions, but only at a column temperature of $26^{\circ} \mathrm{C}$ or when the column temperature was $50^{\circ} \mathrm{C}$ in conjunction with the use of methanol as an entrainer (Method 2). However, at the lower temperature and with the use of methanol as an entrainer, retention times and peak tailing increased for all SGAs. It is worth noting that, when a TEAP buffer was used with the methanol entrainer, separations were not acceptable. As would be expected, at lower temperatures, column back-pressures were higher.

As the ACN concentration approached 70\%, analysis times decreased; however, so did the risk of precipitation of the ammonium dihydrogen phosphate buffer in the HPLC plumbing and pump. Therefore, the conditions chosen as most appropriate for the separation of the aglycones (solasodine and solanidine) were as follows: ACN/ammonium dihydrogen phosphate buffer (60/40), pH: 2.5, and column temperature $26^{\circ} \mathrm{C}$ (Method 3). Since the HPLC system used had a column heater, the same conditions, but at $50^{\circ} \mathrm{C}$, gave sharper peaks for the separation of solasodine and solanidine. When up to $10 \%$ methanol was added as a modifier to the ACN portion of the mobile phase, separation of the aglycones was significantly improved.

\section{Calibration Results}

Representative calibration plots, both with and without using progesterone as an internal standard for solasodine, are shown in Figs. 10 and 11, respectively. Progesterone, an animal hormone, was considered a good choice for an internal standard because it is not expected to be present in the eggplant

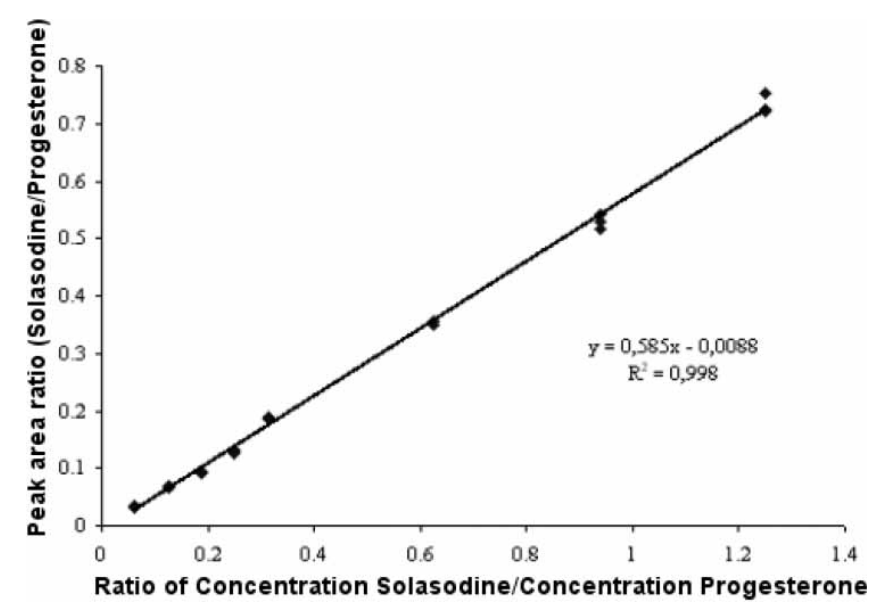

Figure 10. Calibration for solasodine in the concentration range of $4-100 \mathrm{mg} / \mathrm{L}$ with progesterone internal standard. 


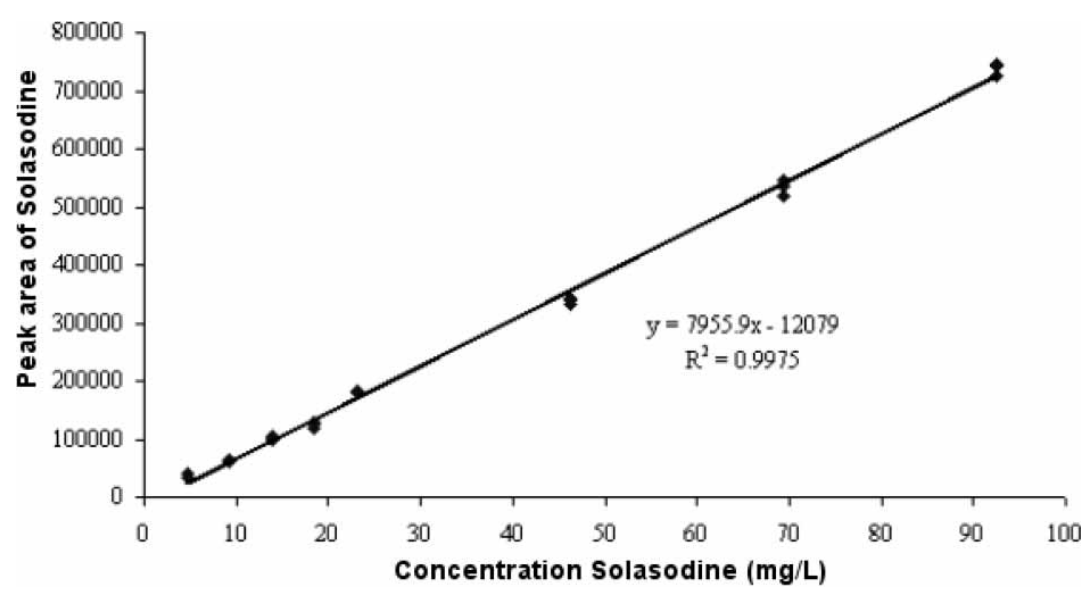

Figure 11. Calibration for solasodine in the concentration range of $4-100 \mathrm{mg} / \mathrm{L}$ without internal standard.

sample and was not found in the extracts obtained. Cholesterol ${ }^{[60]}$ and nicotine ${ }^{[61]}$ have been applied as internal standards for the determination of Solanum glycoalkaloids. However, although they are normally considered to be present only in small quantities, researchers outside this field of study have noted that plants can contain cholesterol. ${ }^{[62]}$ For the calibration plots, good linearity of response was found for solanidine and solasodine, both with and without internal standardization.

If the existing analysis already has acceptable precision, any attempts to improve precision may be offset by a decrease in accuracy. For example, when compared against a standard curve, a solution of $18.0 \mathrm{ppm}$ solasodine that had been prepared in the calibration solvent yielded a determined value of $17.4 \pm 0.2 \mathrm{ppm}$ when using an internal standard. Without the internal standard, however, the determined solasodine concentration was $16.8 \pm 1.3 \mathrm{ppm}$. These results reflect an increase in precision, but a slight decrease in accuracy. Apparently, at least for the HPLC part of the analysis, an internal standard is not required.

Since neither SGAs nor SGAAs could be detected in a commercially acquired $S$. Melongena sample, solasodine was purposely used as a spike to determine the most reliable estimate of recovery. In this manner, S. Melongena and solasodine represented the ideal matrix and internal standard, respectively, yielding a solasodine recovery of approximately $125 \%$. The limit of detection (LOD), defined according to $3 \sigma / \mathrm{m}$ (where $\sigma$ is defined as the error in the calibration curve and $\mathrm{m}$ is the slope of the calibration line) was determined to be $9 \mathrm{mg} / \mathrm{L}$ for solanidine and $1.6 \mathrm{mg} / \mathrm{L}$ for solasodine. Based on an analysis of a Solanum linnaeanum sample, the expected limit of quantitation (LOQ) for solamargine as determined in real samples was between 10 and $20 \mathrm{ppm}$ (corresponding 
to 0.1 to $0.2 \mathrm{mg}$ solamargine per gram of freeze-dried eggplant sample). An average value of $25.5 \pm 11.2 \mathrm{mg}$ solamargine per gram freeze-dried powder was thus taken as the most reliable determined concentration in the tested S. linnaeanum wild-type eggplant sample.

\section{CONCLUSIONS}

The work presented here successfully shows practical improvements to published methods, specifically with regard to the utility of using methanol as a specific HPLC mobile phase entrainer for acetonitrile. The effect of the addition of methanol was dramatic enough that further systematic studies are warranted. Although a gradient method was desired for separation of the six glycoalkaloids and aglycones of interest to future work in this lab, such a method did not give acceptable reproducibility and robustness for routine determination of the analytes over several months, a necessary prerequisite for any long-term study. An isocratic method requires almost no downtime between injections (since re-equilibration is not required). Unfortunately, under no one set of isocratic conditions could all six of the glycoalkaloids of interest be separated. As long as the sample size is sufficient to allow multiple injections, it is much more logical, practical, and economical to optimize the separation of only two of the compounds at a time for each different eggplant sample type that will be analyzed. The greatest advantage in using separate isocratic methods is the focus upon the sure separation of only two compounds and the freedom to make minor adjustments to overcome unforeseen interferences or uncontrollable experimental changes related to column age, temperature, $\mathrm{pH}$, etc. while, at the same time, not having to worry that resolution of the other compounds has decreased. Even though a method to separate all the compounds of interest to this study in a single chromatographic run was desired, it was simply not considered practical by the means employed here. According to their potential to overlap, three isocratic methods were developed for each of the following three compound group pairs: solamargine and chaconine, solanine and solasodine, and the aglycones solasodine and solanidine.

\section{ACKNOWLEDGMENTS}

This research was supported by TUBITAK, (Turkey) Project Number TBAG2364 (103T139) and in part by Izmir Institute of Technology (IZTECH) Project Number 2004 IYTE 31).

\section{REFERENCES}

1. Laurila, J.; Laakso, I.; Larkka, J.; Gavrilenko, T.; Rokka, V.-M.; Pehu, E. The proportions of glycoalkaloid aglycones are dependent on the genome constitutions 
of interspecific hybrids between two Solanum species ( $S$. brevidens and S. tuberosum). Plant Sci. 2001, 161, 677-683.

2. Chen, Z.; Miller, A.R. Steroidal alkaloids in Solanaceous vegetable crops. Horticult. Rev. 2001, 25, 171-196.

3. Friedman, M. Analysis of biologically active compounds in potatoes (Solanum tuberosum), tomatoes (Lycopersicon esculentum), and jimson weed (Datura stramonium) seeds. J. Chromatogr. A. 2004, 1054, 143-155.

4. Turakainen, M.; Vaananen, T.; Anttila, K.; Ollilainen, V.; Hartikainen, H.; Seppanen, M. Effect of selenate supplementation on glycoalkaloid content of potato (Solanum tuberosum L.). J. Agric. Food Chem. 2004, 52, 7139-7143.

5. Weissenberg, M. Isolation of solasodine and other steroidal alkaloids and sapogenins by direct hydrolysis-extraction of Solanum plants or glycosides therefrom. Phytochem. 2001, 58, 501-508.

6. Blankemeyer, J.T.; McWilliams, M.L.; Rayburn, J.R.; Weissenberg, M.; Friedman, M. Developmental toxicology of solamargine and solasonine glycoalkaloids in frog embryos. Food Chem. Toxicol. 1998, 36, 383-389.

7. Mensinga, T.T.; Sips, A.J.A.M.; Rompelberg, C.J.M.; van Twillert, K.; Meulenbelt, J.; van den Top, H.J.; van Egmond, H.P. Potato glycoalkaloids and adverse effects in humans: an ascending dose study. Reg. Toxicol. Pharm. 2005, 41, 66-72.

8. Friedman, M.; Henika, P.R.; Mackey, B.E. Effect of feeding solanidine, solasodine, and tomatidine to non-pregnant and pregnant mice. Food Chem. Toxicol. 2003, 41, 61-71.

9. Cham, B.E.; Meares, H.M. Glycoalkaloids from Solanum sodomaeum are effective in the treatment of skin cancers in man. Cancer Lett. 1987, 36, 111-118.

10. Cham, B.E.; Daunter, B. Solasodine glycosides. Selective cytotoxicity for cancer cells and inhibition of cytotoxicity by rhamnose in mice with sarcoma 180. Cancer Lett. 1990, 55, 221-225.

11. Chang, L.-C.; Tsai, T.-R.; Wang, J.-J.; Lin, C.-N.; Kuo, K.-W. The rhamnose moiety of solamargine plays a crucial role in triggering cell death by apoptosis. Biochem. Biophys. Res. Comm. 1998, 242, 21-25.

12. Kuo, K.-W.; Hsu, S.-H.; Li, Y.-P.; Lin, W.-L.; Liu, L.-F.; Chang, L.-C.; Lin, C.-C.; Lin, C.-N.; Sheu, H.-M. Anticancer activity evaluation of the Solanum glycoalkaloid solamargine-triggering apoptosis in human hepatoma cells. Biochem. Pharm. 2000, 60, 1865-1873.

13. Liang, C.-H.; Liu, L.-F.; Shiu, L.-Y.; Huang, Y.-S.; Chang, L.-C.; Kuo, K.-W. Action of solamargine on TNFs and cisplatin-resistant human lung cancer cells. Biochem. Biophys. Res. Comm. 2004, 322, 751-758.

14. Liu, L.-F.; Liang, C.-H.; Shiu, L.-Y.; Lin, W.-L.; Lin, C.-C.; Kuo, K.-W. Action of solamargine on human lung cancer cells-enhancement of the susceptibility of cancer cells to TNFs. FEBS Lett. 2004, 577, 67-74.

15. Thorne, H.V.; Clarke, G.F.; Skuce, R. The inactivation of herpes simplex virus by some Solanaceae glycoalkaloids. Antiviral Res. 1985, 5, 335-343.

16. Wanyonyi, A.W.; Chabra, S.C.; Mkoji, G.; Eilert, U.; Njue, W.M. Bioactive steroidal alkaloid glycosides from Solanum aculeastrum. Phytochem. 2002, 59, 79-84.

17. Cipollini, M.L.; Levey, D.J. Antifungal activity of Solanum fruit glyc17. alkaloids: Implications for frugivory and seed dispersal. Ecology 1997, 78, 799-809.

18. Attard, G.S.; Morrow, W.J.; Rajananthanan, P. Alkaloid glycoside for use as a medicament. U. S. Pat. 6,673,357, 2004. 
19. Carter, S.J.; Murray, P.E.; Parkin, J.E.; Dalwadi, G. Method for the separation of triglycoalkaloids. U. S. Pat. 6,984,725, 2006.

20. Carter, S.J.; Williams, E. Glycoalkaloid compositions and various uses thereof. U. S. Pat. Application Number 20040249138, 2005.

21. Cham, B.E.; Daunter, B. Glycoalkaloids. U. S. Pat. 5,958,770, 1999.

22. Kuo, K.-W. Water-soluble extract from plant of Solanum genus and the preparation process thereof, and pharmaceutical composition containing the watersoluble extract. U. S. Pat. 7,078,063, 2006.

23. Kuo, K.-W.; Lin, C.-N. Pharmacological composition for treating cancer cells. U. S. Pat. 6,214,803, 1999.

24. Lawson, C. Solvent extraction process. U. S. Pat. Application Number 20040249138, 2004.

25. Moehs, C.P.; Allen, P.V.; Rockhold, D.R.; Stapleton, A.; Friedman, M.; Belknap, W.R. DNA sequences from potato encoding solanidine UDP-glucose glucosyltransferase and use to reduce glycoalkaloids in solanaceous plants. U. S. Pat. 5,959,180, 1999.

26. Stanker, L.H.; Holtzapple, C.K.; Friedman, M. Monoclonal antibodies to potato, tomato, and eggplant glycoalkaloids and assays for the same. U. S. Pat. 5,614,408, 1997.

27. Kuronen, P.; Vaananen, T.; Pehu, E. Reversed-phase liquid chromatographic separation and simultaneous profiling of steroidal glycoalkaloids and their aglycones. J. Chromatogr. A. 1999, 863, 25-35.

28. Kittipongpatana, N.; Porter, J.R.; Hock, R.S. An improved high performance liquid chromatographic method for the quantification of solasodine. Phytochem. Anal. 1999, 10, 26-31.

29. Saito, K.; Horie, M.; Hoshino, Y.; Nose, N.; Nakazawa, H. High-performance liquid chromatographic determination of glycoalkaloids in potato products. J. Chromatogr 1990, 508, 141-147.

30. Friedman, M.; Levin, C.E. Reversed-phase high-performance liquid chromatographic separation of potato glycoalkaloids and hydrolysis products on acidic columns. J. Agric. Food Chem. 1992, 40, 2157-2163.

31. Carman, A.S. Jr.; Kuan S.S.; Ware, G.M.; Francis, O.J. Jr.; Kirschenheuter G.P. Rapid high-performance liquid chromatographic determination of the potato glycoalkaloids alpha-solanine and alpa-chaconine. J. Agric. Food. Chem. 1986, 34, 279-282.

32. Bushway, R.J.; Bureau, J.L.; King, J. Modification of the rapid high-performance liquid chromatographic method for the determination of potato glycoalkaloids. J. Agric. Food Chem. 1986, 34, 277-279.

33. Dao, L.; Friedman, M. Comparison of glycoalkaloid content of fresh and freezedried potato leaves determined by HPLC and colorimetry. J. Agric. Food Chem. 1996, 44, 2287-2291.

34. Edwards, E.J.; Cobb, A.H. Improved high-performance liquid chromatographic method for the analysis of potato (Solanum tuberosum) glycoalkaloids. J. Agric. Food Chem. 1996, 44, 2705-2709.

35. Kozukue, N.; Misoo, S.; Yamada, T.; Kamijima, O.; Friedman, M. Inheritance of morphological characters and glycoalkaloids in potatoes of somatic hybrids between dihaploid Solanum acaule and Tetraploid Solanum tuberosum. J. Agric. Food Chem. 1999, 47, 4478-4483.

36. Sotelo, A.; Serrano, B. High-performance liquid chromatographic determination of the glycoalkaloids alpha-solanine and alpha-chaconine in 12 commercial varieties of Mexican potato. J. Agric. Food Chem. 2000, 48, 2472-2475. 
37. Vaananen, T.; Kuronen, P.; Pehu, E. Comparison of commercial solid-phase extraction sorbents for the sample preparation of potato glycoalkaloids. J. Chromatogr. A. 2000, 869, 301-305.

38. Stobiecki, M.; Matysiak-Kata, I.; Franski, R.; Skala, J.; Szopa, J. Monitoring changes in anthocyanin and steroid alkaloid glycoside content in lines of transgenic potato plants using liquid chromatography/mass spectrometry. Phytochem. 2003, 62, 959-969.

39. Friedman, M.; Roitman, J.N.; Kozukue, N. Glycoalkaloid and calystegine contents of eight potato cultivars. J. Agric. Food Chem. 2003, 51, 2964-2973.

40. Bacigalupo, M.A.; Longhi, R.; Meroni, G. Alpha-solanine and alpha-chaconine glycoalkaloid assay in Solanum tuberosum extracts by liposomes and timeresolved fluorescence. J. Food Comp. Anal. 2004, 17, 665-673.

41. Abreu, P.; Relva, A.; Matthew, S.; Gomes, Z.; Morais, Z. High-performance liquid chromatographic determination of glycoalkaloids in potatoes from conventional, integrated, and organic crop systems. Food Contr 2007, 18, 40-44.

42. Aubert, S.; Daunay, M.C.; Pochard, E. Saponosides steroidiques de l'aubergine (Solanum melonga L.) I. Interet alimentaire, methodologie d'analyse, localisation dans le fruit. Agronomie 1989, 9, 641-651.

43. Aubert, S.; Daunay, M.C.; Pochard, E. Saponosides steroidiques de l'aubergine (Solanum melonga L.) II. Variations des teneurs liees aux conditions de recolte, aux genotypes et a la quantite de graines des fruits. Agronomie 1989, 9, 751-758.

44. Fukuhara, K.; Kubo, I. Isolation of steroidal glycoalkaloids from Solanum incanum by two countercurrent chromatographic methods. Phytochem. 1991, 30, 685-687.

45. Friedman, M.; Bautista, F.F.; Stanker, L.H.; Larkin, K.A. Analysis of potato glycoalkaloids by a new ELISA kit. J. Agric. Food Chem. 1998, 46, 5097-5102.

46. Thomson, C.A.; Sporns, P. Fluorescence polarization imunoassays for potato glycoalkaloids. J. Agric. Food Chem. 1995, 43, 254-260.

47. Driedger, D.R.; LeBlanc, R.J.; Leblanc, E.L.; Sporns, P. A capillary electrophoresis laser-induced fluorescence method for analysis of potato glycoalkaloids based on a solution-phase immunoassay. 2. Performance evaluation. J. Agric. Food Chem. 2000, 48, 4079-4082.

48. Laurila, J.; Laakso, I.; Vaananen, T.; Kuronen, P.; Huopalahti, R.; Pehu, E. Determination of solanidine- and tomatidine-type glycoalkaloid aglycons by gas chromatography/mass spectrometry. J. Agric. Food Chem. 1999, 47, 2738-2742.

49. Zywicki, B.; Catchpole, G.; Draper, J.; Fiehn, O. Comparison of rapid liquid chromatography-electrospray ionization tandem mass spectrometry methods for determination of glycoalkaloids in transgenic field-grown potatoes. Anal. Biochem. 2005, 336, 178-186.

50. Abell, D.C.; Sporns, P. Rapid quantitation of potato glycoalkaloids by matrixassisted laser desorption/ionization time-of-flight mass spectrometry. J. Agric. Food Chem. 1996, 44, 2292-2296.

51. Kreft, S.; Zel, J.; Pukl, M.; Umek, A.; Strukelj, B. Non-aqueous capillary electrophoresis for the simultaneous analysis of solasodine and solanidine. Phytochem. 2000, 11, 37-40.

52. Cherokaoui, S.; Bekkouche, K.; Christen, P.; Veuthey, J.-L. Non-aqueous capillary electrophoresis with diode array and electrospray mass spectrometric detection for the analysis of selected steroidal alkaloids in plant extracts. J. Chromatogr. A. 2001, 922, 321-328.

53. Bianco, G.; Schmitt-Kopplin, P.; De Benedetto, G.; Kettrup, A.; Cataldi, T.R.I. Determination of glycoalkaloids and relative aglycones by nonaqueous capillary 
electrophoresis coupled with electrospray ionization-ion trap mass spectrometry. Electrophoresis 2002, 23, 2904-2912.

54. Kodamatani, H.; Saito, K.; Niina, N.; Yamazaki, S.; Tanaka, Y. Simple and sensitive method for determination of glycoalkaloids in potato tubers by highperformance liquid chromatography with chemiluminescence detection. J. Chromatogr. A. 2005, 1100, 26-31.

55. Usubillaga, A.; Aziz, I.; Tettamanzi, M.C.; Waibel, R.; Achenbach, H. Steroidal alkaloids from Solanum sycophanta. Phytochem. 1997, 44, 537-543.

56. Harborne, J.B. Phytochemical Methods, 3rd Edn.; Chapman \& Hall: London, 1998.

57. Snyder, L.R.; Kirkland, J.J.; Glajch, J.L. Practical HPLC Method Development, 2nd Edn.; John Wiley \& Sons, Inc: New York, 1997.

58. Cipollini, M.L. Personal email communication. Wednesday, Nov. 3, 2004.

59. Sigma Aldrich TEAP Buffer General Product Information; Sigma-Aldrich: St. Louis, Missouri, USA, 2007.

60. Simons, V.; Morrissey, J.P.; Latijnhouwers, M.; Csukai, M.; Cleaver, A.; Yarrow, C.; Osbourn, A. Dual effects of plant steroidal alkaloids on Saccharomyces cerevisiae. Antimicrob. Agents Chemother. 2006, 50, 2732-2740.

61. Eldridge, A.C.; Hockridge, M.E. High-performance liquid chromatographic separation of Eastern black nightshade (Solanum ptycanthum) glycoalkaloids. J. Agric. Food Chem. 1983, 31, 1218-1220.

62. Behrman, E.J.; Gopalan, V. Cholesterol and plants. J. Chem. Ed. 2005, 82, 1791- 1793.

Received September 30, 2007

Accepted November 19, 2007

Manuscript 6226 